\title{
INVESTIGATING EFFECTS OF AMINE BASED MODIFIER ON RECYCLED ASPHALT SHINGLES BLENDING
}

\author{
Govinda Sedhay, Elham H. Fini and Taher Abu-Lebdeh \\ Department of Civil, Architectural and Environmental Engineering, \\ North Carolina A and T State University, NC 27411, Greensboro, USA
}

Received 2014-01-31; Revised 2014-02-13; Accepted 2014-03-26

\begin{abstract}
A laboratory study was conducted to investigate the effects of Amine based modifier on rheological characteristics of particle filled viscous medium such as asphalt binder in presence of Recycled Asphalt Shingles (RAS). In this study, virgin asphalt binder (PG 64-22), three different percentages (20, 30 and $40 \%$ ) of tear-off shingles and modifiers; Rediset, Evotherm and Bio-binder were used. The tear-off shingles acquired from local reroofing company in Greensboro, North Carolina; were finely grinded (85\% passing of sieve \# 200). The virgin binder and different percentages of RAS were then blended at $180^{\circ} \mathrm{C}$ using shearing speed of $400 \mathrm{rpm}$. Following that themixture was blended with $1.5 \%$ of Rediset, $0.5 \%$ of Evotherm and $5 \%$ of bio-binder. The properties of the blended binder were studied using the Rotational Viscometer (RV) equipped with two different spindle types:- One was Smooth Cylindrical spindle (SC4-27D) and the other one was Vane spindle (V 73). The analysis showed that the viscosity was increased with increasing the RAS percentage. Furthermore, the viscosity measured by vane spindle was continuously higher than the value measured by smooth spindle; however the difference between the two measurements reduced as the blending were improved using modifiers. Moreover, temperature found to be the main contributor to reduction of the viscosity in both spindles cases. In addition the coefficient of variation was significantly lower in the case of vane spindle, indicating that the vane spindle could be more appropriate in measuring viscosity of particle filled viscous medium such as RAS asphalt. Based on the experimental result an empirical index called blending index was introduced in this study to measure the blending behavior and status for modified mixtures. As expected it was found that the blending index increases as the temperature and rotational speed increases. In other word, higher temperature and shearing rate could enhance blending resulting in higher blending index. The blending index was further used as a laboratory measure to compare effectiveness of various additives in enhancing blending of RAS modified mixtures. It was shown that among three modifiers used in this study, the bio-binder was more effective to increase the blending index.
\end{abstract}

Keywords: Asphalt Binder, Recycled Asphalt Shingle (RAS), Recycled Asphalt Pavement (RAP), Hot Mix Asphalt (HMA), Modifiers, Theology, Spindle

\section{INTRODUCTION}

Environmental measures are becoming more dominant factors in decision making process of infrastructure and construction projects. In addition because of the fact that the global crude oil price has increased rapidly in the past decades, liquid asphalt price has grown up dramatically to the extent that the price of asphalt increased from $\$ 235 /$ ton in 2004 to more than $\$ 635 /$ ton in April 2013 (DOT, 2013). As a product derived from petroleum distillation, asphalt is becoming less available because the coking technologies allows refineries produce synthetic fuel from asphalt. This in turn, reduces the supply of asphalt available for road Corresponding Author: Elham H. Fini, Department of Civil, Architectural and Environmental Engineering, North Carolina A and T State University, 1601 E. Market Street, Greensboro, NC 27411, USA Tel: (336) 285-3676 Fax: (336) 334-7126 
construction (Cleveland, 1993). Increasing concern for sustainable development and emphasis on materials conservation; re-use and recycling encouraged number of government and highways agencies to commission research and investigations to characterize and ultimately optimize. Recycled materials have to provide added value, i.e., similar performance to conventional materials as well as demonstrating cost effectiveness, in order to be acceptable (Widyatmoko, 2008). That is why pavement industry is emphasizing more and more on recycling of used asphalt resources while looking for substitutes for virgin asphalt (Fini et al., 2011a). Recycle materials could be crumb rubber, polymers, Recycled Asphalt Pavement (RAP), Recycled Asphalt Shingles (RAS), etc which provides attractive alternative solution to address the scarcity of the natural/virgin materials. Among these resources the use of RAS in road construction has been receiving more and more attention in recent years to reduce the consumption of the virgin asphalt binder.

In the construction and rehabilitation of asphalt pavements, large amounts of natural resources are used as aggregates and binders. These resources are limited and therefore the incorporation and reuse of bituminous aged asphalt is important and justified either by environmental issues or by economical. In US, more than 11 million tons of asphalt roofing materials are removed from roof every year (From Roof to Road, CIWMB). Among them 10 million tons from post-consumer (tearoff) and 1 million tons from post-consumer (manufacture scrap) which is the huge amount that will goes in waste. In fact, Roofing Asphalt Shingles (RAS) has been used in paving practices since early 1990's as a portion of aggregate but in recent it has been used as binder in Hot Mix Asphalt (HMA). To date, some of the state agencies have allowed RAS to be used with certain maximum percentages in Hot Mix Asphalt (HMA). The maximum allowed percentage of RAS in most states has been around $5 \%$ by weight of the total aggregate. Some states limit allowable RAS type to only manufacture scrap, while other allow for application of tear-offs as well. For example, following the supplemental specification issued in 2011, the state of Ohio allowed the use of either manufacture's RAS or tear-off RAS depending on the particular pavement course (DOT, 2011). Figure 1 shows the states that currently allows the utilization of RAS in HMA.

Many past studies showed that introduction of shingles into asphalt mixture can increase the stiffness of the mixtures which can in turn promote pavement resistance to rutting.

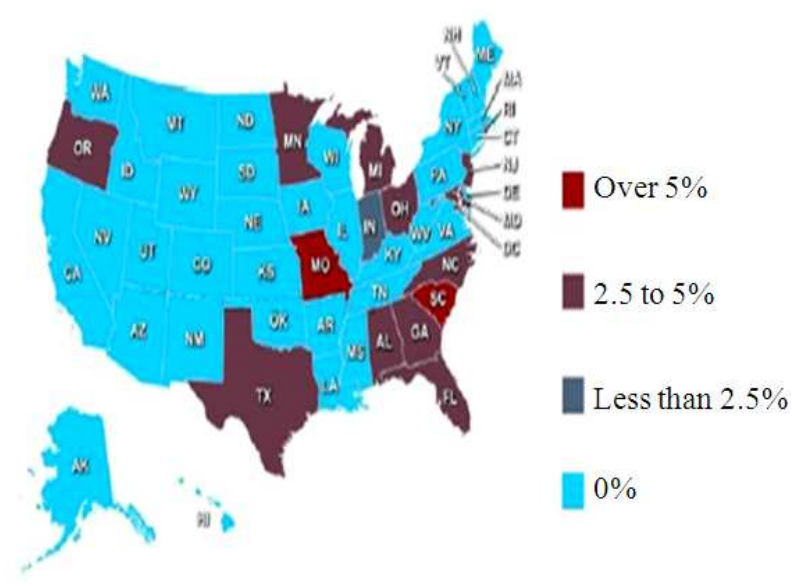

Fig. 1. Allowable percent of RAS in HMA (Scholz, 2010)

In addition application of roofing shingles can lead to reduction of virgin asphalt consumption required to produce HMA mixture. Laboratory studies indicated that incorporating shingle in asphalt mixture tends to improve temperature susceptibility and rutting resistance as well as fatigue life of pavement (Ali et al., 1995).

To studied the effect of introducing of the roofing shingles on the engineering properties of HMA by Burak and Ali (2004); and he found that the Marshall Stability values was increased when $1 \%$ shingle is introduced into the mixture. Moreover, the increased percentage shingle cause decreased the stability values. It has been also showed that at the concentration of up to $5 \%$ shingle, the stability values of mixture are still higher than the minimum value of the specification criteria; therefore, the resulting mixture meets the specification criteria. In addition, it has been reported that by incorporating $5 \%$ shingle in pavement construction, contractors can reduce the construction cost by $\$ 2.79 /$ ton (Brock and Shaw, 1989). It has been further reported that introduction of shingles into asphalt can cause a significant increase in the stiffness of the asphalt binder (Foo et al., 1999). The use of shingle in a HMA mixture will generally improve the rutting resistance; however the mixture may show lower fatigue life and lower thermal cracking resistance. In such cases it has been recommended that the use of an appropriate softer virgin binder or modifiers to improve the fatigue and low temperature performance of the mixture.

There have been several studies on how to facilitate application of RAS without compromising workability and mechanical properties of the mixture including application of softer binder, mechanical grinding and wet 
processing as well as introduction of bio-binder to enhance workability (Mogawer et al., 2012). Grinding to ultra-fine particle size and blending with asphalt binder through a wet process has been reported to be effective in facilitating application of high percentage of RAS (Elseifi et al., 2012). In the wet process, the ground RAS is blended with the binder at high temperature prior to mixing with the aggregates. The proposed wet process allows for a better control of the chemical and physical reaction which occurs in the binder blend. Results of the rheological and stability testing indicate that RAS percentage as much as $20 \%$ can successfully used through a wet process.

From this study it was found that the aged RAS is the main constituent to increase the viscosity of the mixture which cause many distress on the pavement during preparation, compaction, mixing etc. So to address this issue many other softer binders also called modifiers has been in practices. As example Sasobit, Rediset, evotherm, bio- binder etc. And modifier have been used according to its properties and design guidelines. In order to establishing a design method suitable for a warm recycled mix has been studied in recent time through different test method. Dinis-Almeida et al. (2012) conducted the Marshall test, immersion compression test, water sensitivity test in his study and concluded that the temperature production and compaction of the mixtures influences the final results. In addition the best result were obtained for the mixtures compacted at $90^{\circ} \mathrm{C}$ and the mixtures compacted at $60^{\circ} \mathrm{C}$, in most cases were excluded for failing to meet specified requirements.

\section{EXPERIMENTAL PROGRAM}

An experimental program was developed to investigate the effect of amine based modifiers addition on the rheological properties of recycled asphalt materials. Three different percentages of RAS modified mixtures were mixed with three different amine based modifiers separately. An empirical formula was proposed to identify the blending behaviors of the designed modified mixtures.

\subsection{Materials}

\subsubsection{Virgin Binder}

Un-modified binder which was classified as PG 6422 according to the Superpave specification was selected for this study. It was used in an attempt to offset the potential mixture stiffening due to the use of high percentage of RAS in the mixture. Based on the viscosity of the binder, the mixing temperature was $180^{\circ} \mathrm{C}$. Table 1 shows properties of the virgin binder.

\subsubsection{Roofing Asphalt Shingles (RAS)}

The tear-off shingles used for this experiment was obtained from a local roofing company in Greensboro, North Carolina. Shingle was processed by grinding followed by sieving. An industrial Hamilton Beach grinder was used to create particles with $85 \%$ passing of sieve \#200.

To conduct the experiment the virgin asphalt binder (PG 64-22) was blended with different percentages of RAS ranging from 20 to $40 \%$. Mixing was performed utilizing a laterally attached oscillating mixer. Shearing was conducted at $400 \mathrm{rpm}$ at $180^{\circ} \mathrm{C}$. Mixing duration was $60 \mathrm{~min}$.

\subsubsection{Bio-Binder}

Bio-binder is derived from non-petroleum based renewable resources like wood and corn. Recently, research efforts have suggested using a bio-binder along with the petroleum based asphalt to produce a biomodified binder (Fini et al., 2011b; 2012). So the biobinder could be an alternative to petroleum based asphalts. In this study bio-binder used was produced by thermochemical liquefaction processing of swine manure under relatively high Temperature $(\mathrm{T}=$ $\left.340^{\circ} \mathrm{C}\right)$ and Pressure $(\mathrm{P}=10.3 \mathrm{MPa})$ for specific Residence Times ( $\mathrm{RT}=80 \mathrm{~min}$ ) is used to produce bio-oil and utilizes the heavy residue remaining in this process as an asphalt modifier. Table $\mathbf{2}$ shows chemical composition of bio-binder and asphalt.

\subsubsection{Rediset}

The modifier Rediset can also treated as warm mix asphalt which lower compaction temperature needs lower optimum binder content to conform to the mix design criteria, it's stability and quotient is lower than mixture fabrication at high temperatures. The lower temperature leads to less energy consumption and lower emissions production at the asphalt mixing plants. Study showed that Optimum Binder Content (OBC) of Warm Mix Asphalt (WMA) is slightly lower than the OBC for HMA without warm additive rediset and furthermore the higher rediset content slightly decreases the asphalt mixture stability but increase the VFA. It implies that higher rediset content has a softening role in the asphalt mixtures (Hamzaha et al., 2013) which enhance the homogeneity of the binder. Table 3 shows the recommended doses. 
Table 1. Properties of base binder PG 64-22

\begin{tabular}{llll}
\hline $\begin{array}{l}\text { Specific } \\
\text { gravity } @ 15.6^{\circ} \mathrm{C}\end{array}$ & $\begin{array}{l}\text { Flash point, } \\
\text { cleveland open Cup, }{ }^{\circ} \mathrm{C}\end{array}$ & $\begin{array}{l}\text { Change in } \\
\text { mass RTFO }\end{array}$ & $\begin{array}{l}\text { Absolute viscosity } \\
\text { at } 60^{\circ} \mathrm{C}, \text { Pa.s }\end{array}$ \\
\hline 1.039 & 335 & -0.0129 & 202 \\
\hline
\end{tabular}

Table 2. Comparison of chemical composition of bio-binder and asphalt (Fini et al., 2011b; 2012)

\begin{tabular}{lrc}
\hline Component $(\% \mathrm{wt})$ & Bio binder & AAD-1 \\
\hline Carbon $(\mathrm{C})$ & 72.58 & 81.60 \\
Hydrogen $(\mathrm{H})$ & 9.76 & 10.80 \\
Nitrogen $(\mathrm{N})$ & 4.47 & 0.77 \\
Oxygen $(\mathrm{O})$ & 13.19 & 0.90 \\
Water content & 2.37 & \\
Ash content & 0.13 & \\
\hline
\end{tabular}

Table 3. Recommended doses of liquid rediset by wt. of mixture (AkzoNobel Surface Chemistry)

\begin{tabular}{ll}
\hline Application & Doses (\%) \\
\hline Warm-mix (Standard paving and PG grades) & $0.4-0.6$ \\
Compaction Aid & $0.3-0.5$ \\
High-RAP, PMB and higher PG binders & $0.5-0.75$ \\
Foam warm-mixes & $0.3-0.5$ \\
\hline
\end{tabular}

\subsubsection{Evotherm}

Evotherm technology is important to using it successfully in asphalt pavement construction projects. Evotherm WMA is a comprehensive chemical additive system designed to allow the production and compaction of high quality asphalt pavements at temperatures as much as $100^{\circ} \mathrm{F}$ lower than conventional HMA. The benefit is the reduction in the consumption of energy when manufacturing the asphalt mixes, as the job materials need to be heated less than when manufacturing the conventional hot mix. Various job sites have shown a savings of around $40 \%$ in energy (Maze et al., 2003), with measured gains from 35 to $55 \%$ depending on the moisture content of the aggregate materials and the ambient weather conditions. In addition the reduction temperature is a significant drop in the emission rates of stack gases and particulates at the mix plant. One study showed the $48 \%$ reduction in greenhouse gases, $58 \%$ reduction in nitrogen oxides and $41 \%$ reduction in Sulpher dioxide, which is responsible for acid rain (Maze et al., 2003).

\subsection{Specimen Preparation}

As described Table 4, to conduct the study, three different percentages of RAS and three different modifiers were designed. All together 24 specimen were made; three sample were made only RAS with virgin binder no modifier here called control, three were control and Rediset, three were control and Evotherm and three were control and Bio- binder for spindle SC4-27 and same amount of specimen were made for V73 spindle. Here the doses of modifiers were chosen $1.5 \%$ for Rediset, $0.5 \%$ for Evotherm and 5\% for Bio-binder by weight of mixture. To make homogeneous mixture RAS and virgin asphalt was blended at $400 \mathrm{rpm}$ at $180^{\circ} \mathrm{C}$ during $60 \mathrm{~min}$ for each percentage of RAS; similarly each type of modifiers were then blended at $400 \mathrm{rpm}$ and at $130^{\circ} \mathrm{C}$ during $20 \mathrm{~min}$ separately for each RAS percentages. Mixing was performed utilizing a laterally attached oscillating mixer, then from each blended mixture $10.5 \mathrm{gm}$ specimen was poured in aluminum chamber. The chamber/tube was then placed into a preheated thermosel during $20 \mathrm{~min}$. To measure the viscosity a Brookfield viscometer was chosen.

\section{TEST PROCEDURES}

\subsection{Viscosity Measurement}

Study was conducted to measure viscosity of the all prepared specimen at different temperatures and shear rates using a Brookfield viscometer (RV-DVIII Ultra) following ASTM D4402 test procedure. To prepare specimens, the authors poured $10.5 \mathrm{~g}$ of each material into different aluminum chambers to gain a better sampling of the entire blend. They then placed the tubes into a 30-min preheated thermosel to reach thermal equilibrium. To investigate properties of the modified binders, they run the test at $105,120,1357150^{\circ} \mathrm{C}$ at speeds of 5,10,20,25, 50 and $100 \mathrm{rpm}$. Then the authors preheated the sample and thermosel at its designed temperature for an additional $20 \mathrm{~min}$ to ensure the achievement of thermal equilibrium. They used two spindle SC4-27D and Vane Spindle V73 separately (Brookfield Engineering, Middleboro, MA) for testing and conducted the first viscosity reading after $15 \mathrm{~min}$ of shearing. Then, they recorded three more results in 3 min intervals to ensure consistency of viscosity measurement. Table 5 showed the measured viscosity data from both spindles.

\subsection{Blending Index}

Blending index is an indication of degree of blending achieved between the oxidized binder in RAS and virgin binder. 
Table 4. Description of the Test Materials and it's proportions

\begin{tabular}{|c|c|c|c|c|c|c|}
\hline \multirow[b]{2}{*}{ Base binder } & \multirow{2}{*}{$\begin{array}{l}\text { Shingles } \\
\text { content }(\%)\end{array}$} & \multirow{2}{*}{$\begin{array}{l}\text { Source of } \\
\text { materials }\end{array}$} & \multicolumn{4}{|l|}{ Description } \\
\hline & & & Control & Rediser modified & Evotherm modified & Bio-binder modified \\
\hline \multirow[t]{2}{*}{ PG 64-22 } & 20 & Tear-Off & PG 64-22+ & PG 64-22+20\% & PG $64-22+20 \%$ & PG 64-22+20\% \\
\hline & & & $20 \%$ RAS & RAS $+1.5 \%$ Rediset & RAS $+0.5 \%$ Evotherm & RAS $+5 \%$ Bio-binder \\
\hline \multirow[t]{2}{*}{ PG 64-22 } & 30 & Tear-Off & PG 64-22 & PG $64-22+30 \%$ & PG $64-22+30 \%$ & PG $64-22+30 \%$ \\
\hline & & & $+30 \%$ RAS & RAS $+1.5 \%$ Rediset & RAS $+0.5 \%$ Evotherm & RAS $+5 \%$ Bio-binder \\
\hline \multirow[t]{2}{*}{ PG 64-22 } & 40 & Tear-Off & PG 64-22 & PG $64-22+40 \%$ & PG $64-22+40 \%$ & PG $64-22+40 \%$ \\
\hline & & & $+20 \%$ RAS & RAS $+1.5 \%$ Rediset & RAS $+0.5 \%$ Evotherm & RAS $+5 \%$ Biobinder \\
\hline
\end{tabular}

$\underline{\text { Table 5. Measured viscosity of all mixture at } 20 \mathrm{rpm}}$

\begin{tabular}{|c|c|c|c|c|c|c|c|c|c|}
\hline \multirow[b]{2}{*}{ Blend } & \multirow[b]{2}{*}{ Tem. (C) } & \multicolumn{2}{|l|}{ Control } & \multicolumn{2}{|c|}{ Rediset modified } & \multicolumn{2}{|c|}{ Evotherm modified } & \multicolumn{2}{|c|}{ Bio-binder modified } \\
\hline & & $\begin{array}{l}\text { Spindle } \\
\text { (SC27) }\end{array}$ & $\begin{array}{l}\text { Spindle } \\
\text { (V73) }\end{array}$ & $\begin{array}{l}\text { Spindle } \\
\text { (SC27) }\end{array}$ & $\begin{array}{l}\text { Spindle } \\
\text { (V73) }\end{array}$ & $\begin{array}{l}\text { Spindle } \\
\text { (SC27) }\end{array}$ & $\begin{array}{l}\text { Spindle } \\
\text { (V73) }\end{array}$ & $\begin{array}{l}\text { Spindle } \\
\text { (SC27) }\end{array}$ & $\begin{array}{l}\text { Spindle } \\
\text { (V73) }\end{array}$ \\
\hline \multirow[t]{4}{*}{$20 \%$ RAS } & 105 & 5554.33 & 12553.00 & 4045.60 & 8346.60 & 4600.00 & 6902.33 & 3593.00 & 4866.00 \\
\hline & 120 & 1867.00 & 4208.00 & 1358.60 & 2720.00 & 1650.00 & 2434.00 & 1263.00 & 1647.00 \\
\hline & 135 & 737.50 & 1398.00 & 645.00 & 1132.67 & 650.00 & 998.86 & 516.66 & 727.37 \\
\hline & 150 & 350.00 & 715.30 & 304.00 & 553.00 & 350.00 & 463.70 & 280.66 & 345.87 \\
\hline \multirow[t]{4}{*}{$30 \%$ RAS } & 105 & 6715.00 & 13559.00 & 5621.00 & 9669.00 & 5888.00 & 10165.00 & 4117.00 & 6000.00 \\
\hline & 120 & 2183.00 & 4359.00 & 1862.60 & 3272.33 & 1972.00 & 3466.33 & 1429.00 & 2297.00 \\
\hline & 135 & 837.50 & 1676.00 & 720.80 & 1302.00 & 808.33 & 1373.00 & 600.00 & 898.89 \\
\hline & 150 & 391.66 & 731.47 & 337.50 & 633.10 & 395.80 & 642.50 & 287.50 & 397.75 \\
\hline \multirow[t]{4}{*}{$40 \%$ RAS } & 105 & 7275.00 & 17985.00 & 5971.00 & 14278.00 & 7188.00 & 13063.00 & 5979.00 & 7067.00 \\
\hline & 120 & 2393.00 & 4744.00 & 1971.00 & 3932.00 & 2387.60 & 4209.00 & 2000.00 & 2856.00 \\
\hline & 135 & 945.83 & 1864.00 & 820.60 & 1507.00 & 904.00 & 1560.00 & 775.00 & 1163.00 \\
\hline & 150 & 437.50 & 820.36 & 366.60 & 567.70 & 425.00 & 695.50 & 363.00 & 419.00 \\
\hline
\end{tabular}

The blending index of the RAS-modified binder was evaluated using a viscosity variation versus temperature. Using the difference between the two measurements at the same temperature and speed rate, a blending index was defined as follow:

$$
\mathrm{Bx}=\frac{\log \log \left(\eta_{\mathrm{SC} 27}\right)}{\log \log \left(\eta_{\mathrm{v} 73}\right)} * \log \log (\mathrm{T}) * 100 \%
$$

To applying the above formula, the blending indices were calculated for all designed mixture and all temperature at 20 rotational speeds (rpm). And valued were shown in Table 6.

Where:

- $\mathrm{T}$ is the temperature of the binder at known point in Celsius unit $\left({ }^{\circ} \mathrm{C}\right)$

- $\quad \eta_{\mathrm{SC27}}$ and $\eta_{\mathrm{V} 73}$ are the viscosities of the binder at the known points(cP)

\subsection{Temperature Susceptibility}

Temperature susceptibility is a measure of how fast the binder properties changes with temperature changes (Claudy et al., 1998). The temperature susceptibility of the RAS-modified asphalt blends were evaluated by developing Temperature-viscosity plots for the prepared specimens. If an asphalt binder has a high susceptibility to temperature, its viscosity changes rapidly as the temperature changes. Asphalts with high temperature susceptibility are not desirable as they are more prone to thermal and U.V. oxidation (Firoozifar and Foroutan, 2011). Therefore it is important to numerically quantify the temperature susceptibility of the binder. Following equation has been commonly used to calculate the Temperature Susceptibility (VTS) (Rasmussen et al., 2002):

$$
\mathrm{VTS}=\frac{\log \log \left(\eta_{2}\right)-\log \log \left(\eta_{1}\right)}{\log \left(\mathrm{T}_{2}\right)-\log \left(\mathrm{T}_{1}\right)}
$$

Where:

$\mathrm{T}_{1}$ and $\mathrm{T}_{2}=$ The temperature of the binder at known point in Rankin unit (R)

$\eta_{1}$ and $\eta_{2}=$ The viscosities of the binder at the known points (cp)

The magnitude of the VTS is directly proportional to the temperature susceptibility of the binder. 
Table 6. Temperature effects on various modifier modified binder in presence of $20 \%$ RAS

\begin{tabular}{|c|c|c|c|c|c|c|}
\hline \multicolumn{2}{|l|}{ Shear rate } & \multicolumn{4}{|c|}{ Rotational speed (RPM)/log viscosity (cP) } & \multirow[b]{3}{*}{ Average } \\
\hline & & 1.7 & 3.4 & 6.8 & 8.5 & \\
\hline & $\mathrm{T}\left({ }^{\circ} \mathrm{C}\right)$ & 5 & 10 & 20 & 25 & \\
\hline \multirow[t]{2}{*}{ Blend } & 105 & 1.21 & 2.42 & 4.88 & 6.13 & 3.66 \\
\hline & 120 & 1.37 & 2.74 & 5.52 & 6.92 & 4.14 \\
\hline \multirow[t]{2}{*}{ Control } & 135 & 1.57 & 3.16 & 6.36 & 7.98 & 4.77 \\
\hline & 150 & 1.73 & 3.48 & 7.01 & 8.89 & 5.27 \\
\hline VTS & & -3.35 & -3.31 & -3.36 & -3.21 & -3.31 \\
\hline \multirow[t]{4}{*}{ Rediset modified } & 105 & 1.26 & 2.53 & 5.10 & 6.38 & 3.82 \\
\hline & 120 & 1.44 & 2.91 & 5.82 & 7.28 & 4.36 \\
\hline & 135 & 1.59 & 3.25 & 6.55 & 8.20 & 4.90 \\
\hline & 150 & 1.78 & 3.63 & 7.29 & 9.18 & 5.47 \\
\hline VTS & & -3.06 & -3.05 & -3.02 & -3.08 & -3.05 \\
\hline \multirow[t]{4}{*}{ Evotherm modified } & 105 & 1.29 & 3.85 & 5.21 & 6.52 & 4.22 \\
\hline & 120 & 1.46 & 2.94 & 5.91 & 7.39 & 4.42 \\
\hline & 135 & 1.60 & 3.22 & 6.67 & 8.39 & 4.97 \\
\hline & 150 & 1.74 & 3.56 & 7.50 & 9.57 & 5.59 \\
\hline VTS & & -2.64 & -2.67 & -3.10 & -3.27 & -2.92 \\
\hline \multirow[t]{4}{*}{ Bio- binder modified } & 105 & 1.30 & 2.62 & 5.26 & 3.80 & 3.25 \\
\hline & 120 & 1.48 & 2.98 & 5.97 & 7.47 & 4.48 \\
\hline & 135 & 1.68 & 3.37 & 6.74 & 8.44 & 5.06 \\
\hline & 150 & 1.84 & 3.73 & 7.55 & 9.45 & 5.64 \\
\hline VTS & & -3.07 & -2.99 & -3.08 & -3.09 & -3.06 \\
\hline
\end{tabular}

Note: Every nnumber is shown as $103(1 \mathrm{cP} * 103 \mathrm{PaS})$

\section{RESULTS}

Analysis of the data showed that the all modified binder has similar properties in terms of temperature susceptibility. Table 6 presents the all modified binder results for Temperature Susceptibility (VTS) at $20 \%$ RAS content and viscosity measurement at various speeds $(5,10,20,25,50$ and 100), RAS percentages (20, 30 and $40 \%)$ and temperature $(105,120,135$ and $\left.150^{\circ} \mathrm{C}\right)$. The viscosity measurements at $105^{\circ} \mathrm{C}$ of percentage of RAS at 50 and $100 \mathrm{rpm}$ were too high to be measured; therefore, the VTS and blending index values could not be calculated at that rotational speed.

\section{DISCUSSION}

The author founds that the introduction of the amine based modifiers to the RAS mixed asphalt binder was beneficial because of the amine based modifiers influence on reducing the blend's overall viscosity; therefore one can accommodate higher percentages of RAS without depleting the engineering properties. The lower viscosity modified mixture also allows for the mixing and compaction temperature which decrease energy consumption and after all construction cost. A simultaneous comparison of viscosity results from three different amine based modifier binders with control (RAS modified with PG 64-22) showed that modification with the bio-binder led to significant lowering in the asphalt binder's viscosity.

The authors also found that the difference between the viscosity values of the mixtures become less significant at high temperature.

To study the temperature susceptibility of each binder, the authors calculated the VTS values by using Equation 2 and shown in tabular form in Table 6 . The result values was plotted in Fig. 2 and the plots showed that all modifiers (Rediset, Evotherm and Bio-binder) modified mixtures have lower slopes than that of the control binder, which indicating that the temperature susceptibility of the binder was reduced because of the modification with amine based modifiers.

In this figure the temperature susceptibility curves of all binders are above the control binder curve; therefore it can be conclude that binders have less slope and less susceptible than control.

Investigating the blending index of each mixtures, the authors calculated the Bx values by using Equation 1 . They plotted the results for each modified binder at 20, 30 and $40 \%$ of RAS and at 20 rpm in Fig. 3 through 5. 
From Fig. 3, it can be seen that all three modifiers showed comparative increment in Bx with increasing the temperature. Among them Bio-modified binder showed higher Bx values than Evotherm and Rediset modified binder. The blending index value was increased from 29.7 to 32.5 which is $2.8 \%$ increment from 105 to $150^{\circ} \mathrm{C}$.

In Fig. 4, the blending index at $150^{\circ} \mathrm{C}$ is higher than the other temperatures in all binders. The increment in $\mathrm{Bx}$ from 105 to $150^{\circ} \mathrm{C}$ for Rediset modified binder is 1.18 . However, the $\mathrm{Bx}$ increase for
Evotherm modified binder found to be around 2.0 and for Bio-binder modified binder to be $2.3 \%$. Therefore, the increment in bio-binder found to be higher than the other two. Same trend can be seen at $40 \%$ RAS content binder shown in Fig. 5.

Furthermore, the blending indexes of all binders at $135 \mathrm{oC}$ were determined to study which percentage of RAS can lead to improved blending results. It was found that $20 \%$ RAS content binders in all case showed higher value than $40 \%$ RAS content followed by $30 \%$ RAS content. The values were plotted in Fig. 6.

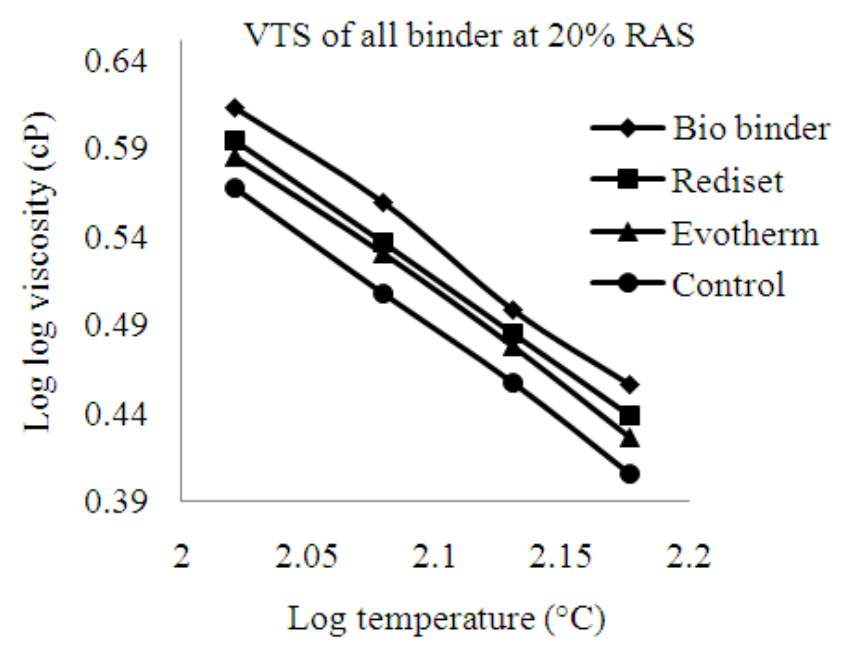

Fig. 2. VTS for all samples at $20 \%$ RAS for V73 spindle values

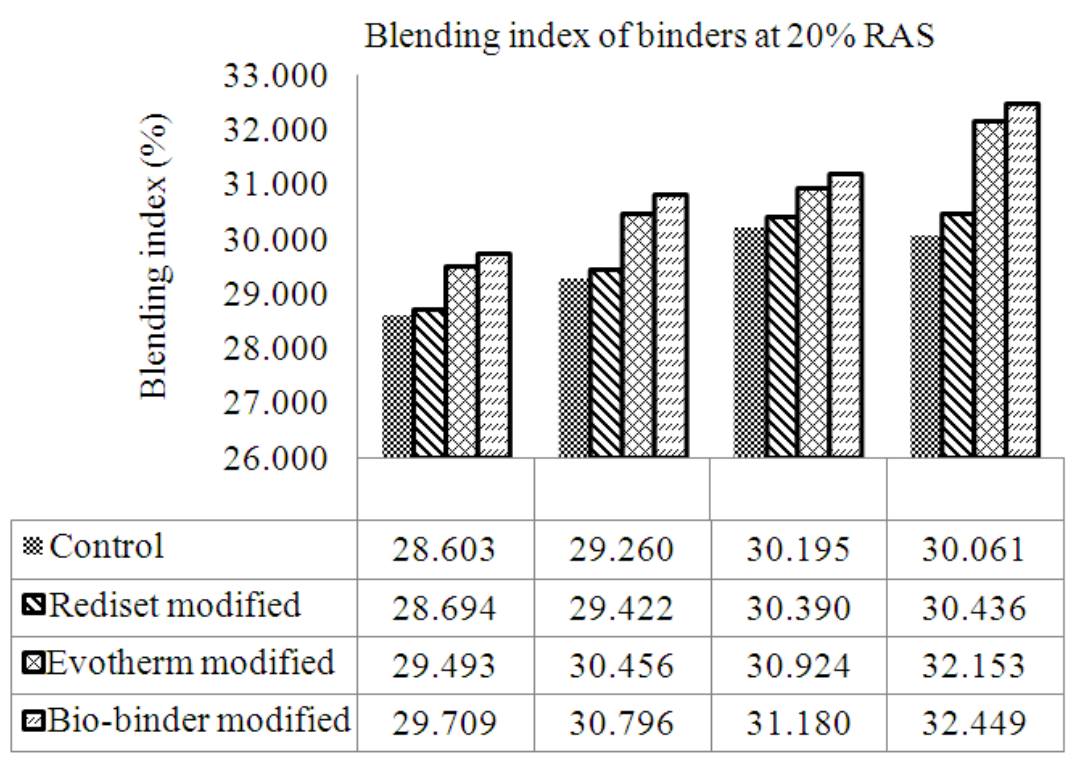

Fig. 3. Bx for all modified binders at $20 \%$ RAS and $105,120,135$ and $150^{\circ} \mathrm{C}$ temperature 


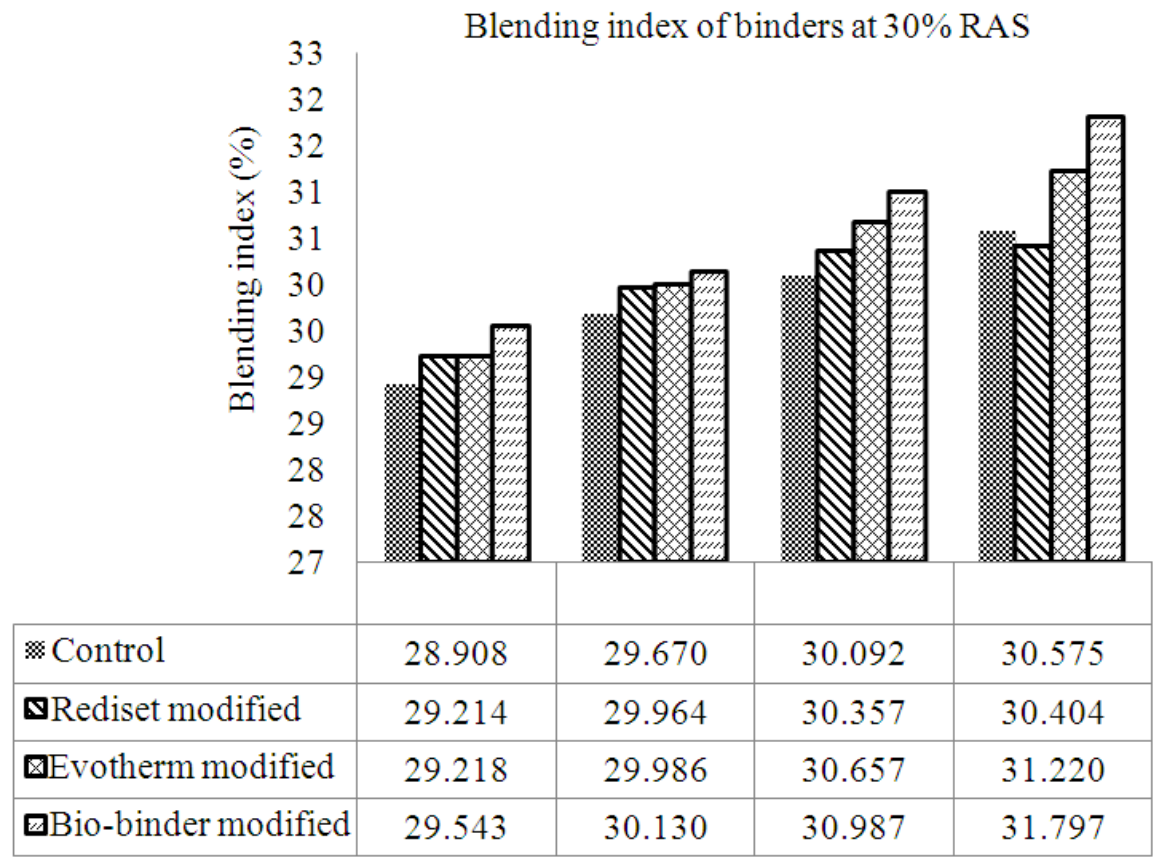

Fig. 4. Bx for all modified binders at $30 \%$ RAS and $105,120,135$ and $150^{\circ} \mathrm{C}$ temperature

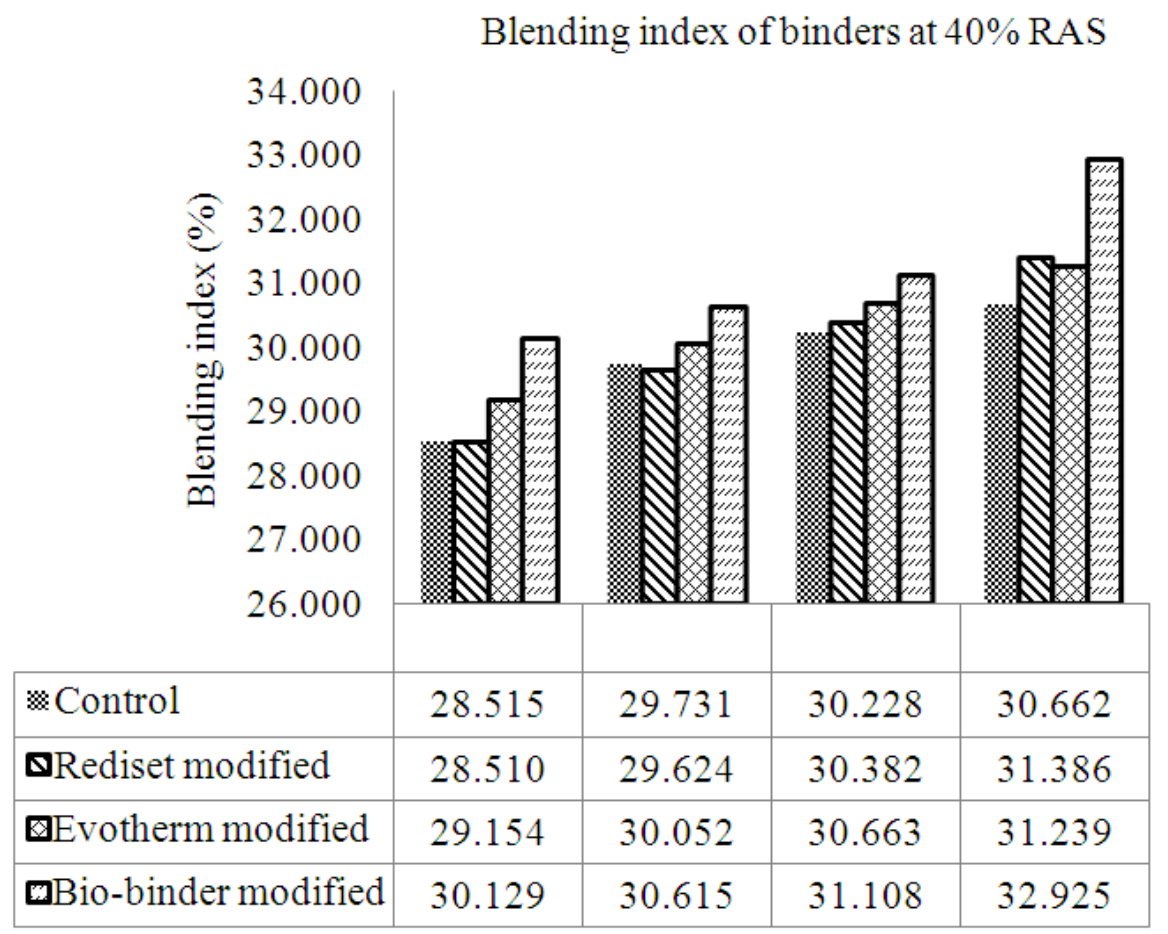

Fig. 5. Bx for all modified binders at $40 \%$ RAS and $105,120,135$ and $150^{\circ} \mathrm{C}$ temperature 


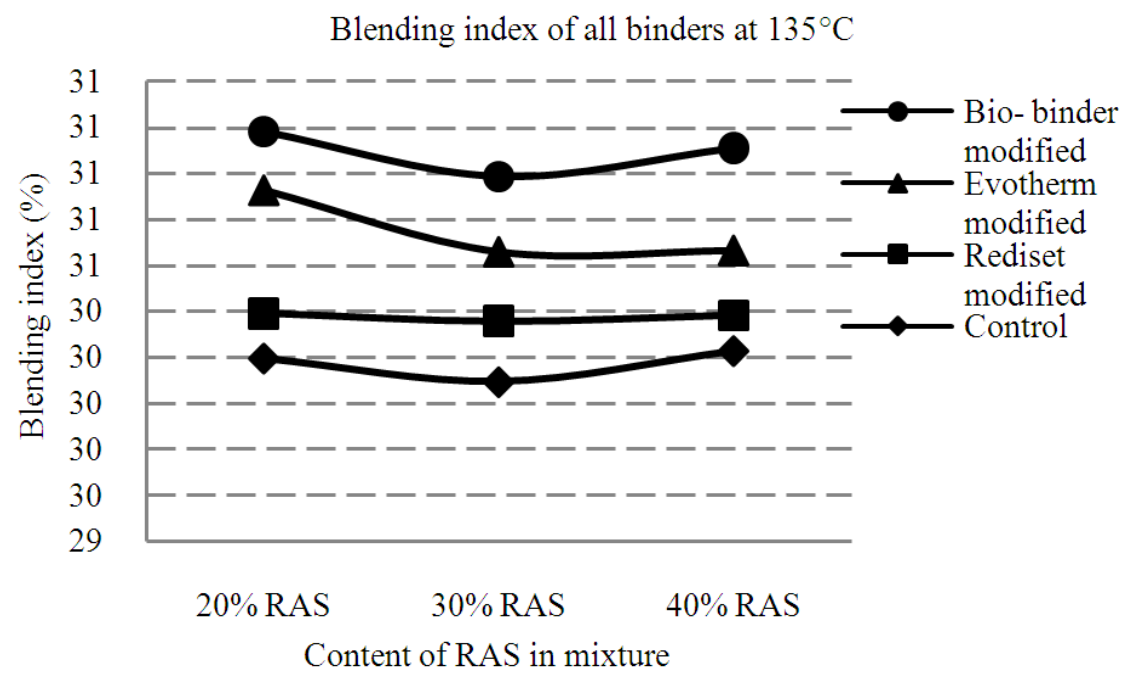

Fig. 6. Change of $\mathrm{Bx}$ of all modified binders at $135^{\circ} \mathrm{C}$ temperature

\section{CONCLUSION}

The viscosities measured from different modified mixture were analyzed through coefficient of variation. Viscosity results showed that the vane spindle consistently shows higher viscosity than smooth spindle. The coefficients of variation were decreased as temperature and rotational speed increased. It was also shown that the coefficient of variation was lower in biobinder modified mixture than those of Rediset and Evotherm modified mixture.

To study the blending status and effectiveness of each modified binder, in this study an empirical index $(\mathrm{Bx})$ was introduced Calculating $\mathrm{Bx}$ for three different modifiers in this study, it was shown that all modifiers effectively increased the blending index of RAS mixtures. It was further found out that bio-binder could be more effective in enhancing blending index than Rediset and Evotherm.

In addition, the study of the temperature susceptibility showed all three modifiers can improve temperature susceptibility compared to control binder. Among the three modified binder, bio modified binder showed less temperature susceptibility than other two modified binder.

\section{REFERENCES}

Ali, N., J.S. Chan, A. Potyondy, R. Bushman and A. Bergen, 1995. Mechanistic evaluation of asphalt concrete mixtures containing reclaimed roofing materials. Trans. Res. Record, 1515: 28-36.
Brock, J.D. and D. Shaw, 1989. From roofing shingles to roads. Technical Paper T-120. Astec Industries, Chattanooga, TN.

Burak, S. and T. Ali, 2004. Use of asphalt roofing shingles waste in Hot Mix Asphalt. J. Construction Build. Materials 19: 337-346.

Claudy, P.M., D. Martin and J.P. Planche, 1998. Thermal behavior of asphalt cements. Thermochimica Acta, 324: 203-213. DOI: 10.1016/S0040-6031(98)00537-1

Cleveland, C.J., 1993. An exploration of alternative measures of natural resource scarcity: The case of petroleum resources in the U.S. Economical Econom., 7: 123-157. DOI: 10.1016/09218009(93)90050-G

Dinis-Almeida, M., J.C. Gomes and M.L. Antunes, 2012. Mix design considerations for warm mix recycled asphalt with bitumen emulsion. Construction Build. Materials, 28: 687-693. DOI: 10.1016/j.conbuildmat.2011.10.053

Elseifi, A.M., S. Salari, N.L. Mohammad, M. Hassan and H.W. Daly et al., 2012. A new approach to recycle asphalt shingles in hot mix asphalt. J. Materials Civil Eng., 24: 1403-1411.

Fini, E.H., E. Kalberer and A. Shahbazi, 2011a. Biobinder from swine manure: Sustainable alternative for asphalt binder. Proceedings of the TRB 90th Annual Meeting, (TAM' 11), Washington DC, pp: 15-15. 
Fini, E.H., E.W. Kalberer, G. Shahbazi, M. Basti and Z. You et al., 2011b. Chemical characterization of biobinder from swine manure: Sustainable modifier for asphalt binder. J. Materials Civil Eng., 23: 15061513. DOI: 10.1061/(ASCE)MT.19435533.0000237

Fini, H.E., L.I. Al-Qadi, Z. You, B. Zada and M.J. Beale, 2012. Partial replacement of asphalt binder with biobinder: Characterization and modification. Int. J. Pavement Eng., 13: 515-522. DOI: 10.1080/10298436.2011.596937

Firoozifar, S. and S. Foroutan, 2011. The effect of asphaltene on thermal properties of bitumen. Chem. Eng. Res. Design, 89: 2044-2048. DOI: 10.1016/j.cherd.2011.01.025

Foo, K., D. Hanson and T. Lynn, 1999. Evaluation of roofing asphalt in hot mix asphalt. J. Materials Civil Eng., 11: 15-20.

Hamzaha, M.O., B. Golchina and T.T. Ching, 2013. Determination of the optimum binder content of warm mix asphalt incorporating Rediset using response surface method. Construct. Build. Materials, 47: 1328-1336. DOI: 10.1016/j.conbuildmat.2013.06.023

Maze, M., F. Delfosse, S.F. Dumont, 2003. Development of the Tempera $\AA /$ Evotherm $\mathrm{DAT}^{\mathrm{TM}}$ process in Europe: A collaboration between eurovia and MeadWestvaco. Specialty Chemicals.
Mogawer, S.W., H.E. Fini, J.A. Austerman, A. Booshehrian and B. Zada, 2012. Performance characteristics of high rap bio-modified asphalt mixtures. Proceedings of the Transportation of Research Board 91st Annual Meeting, (BAM' 12), Washington, DC, pp: 16-16.

DOT, 2013. Fuel, asphalt and steel price adjustments. Department of Transportation.

DOT, 2011. Supplemental Specification 800, Revision to the 2010 Construction and Material Specifications.

Rasmussen, R., R. Lytton and G. Chang, 2002. Method to predict temperature susceptibility of an asphalt binder. J. Materials Civil Eng., 14: 246252. DOI: $10.1061 /(\mathrm{ASCE}) 0899$ 1561(2002)14:3(246)

Scholz, V.T., 2010. Preliminary investigation of RAP and RAS in hot mix asphalt cement. Oregon Department of Transportation Research Section.

Widyatmoko, I., 2008. Mechanistic-empirical mixture design for hot mix asphalt pavement recycling. Construct. Build. Materials, 22: 77-87. DOI: 10.1016/j.conbuildmat.2006.05.041 